\title{
Risk Assessment Approach for Prioritizing Danube Basin-Specific Pollutants: a Case Study in the Novi Sad Region
}

\author{
Dusan Milovanovic ${ }^{1}$, Ivan Spanik², Mirjana Vojinovic Miloradov ${ }^{1}$, Ivana Mihajlovic ${ }^{1}$, \\ Jelena Radonic ${ }^{1}$, Andrea Machynakova ${ }^{2}$, Maja Petrovic ${ }^{1 *}$ \\ ${ }^{1}$ Department of Environmental Engineering, Faculty of Technical Sciences, University of Novi Sad, Novi Sad, Serbia \\ ${ }^{2}$ Institute of Analytical Chemistry, Faculty of Chemical and Food Technology, Slovak University \\ of Technology in Bratislava, Bratislava, Slovak Republic
}

Received: 29 July 2018

Accepted: 18 October 2018

\begin{abstract}
The aim of this work was to determine the most relevant pollutants in Danube surface water and wastewater in the city of Novi Sad, and to conduct a risk assessment approach on substances for the optimization of future monitoring programmes. According to the requirements of Serbian law, obligatory and operating monitoring was focused on physico-chemical and biological parameters while the expanded monitoring programmes have not been applied - often due to practical circumstances. Novi Sad, with a population of more than 300.000 inhabitants, does not have a wastewater treatment plant, and about $2 \mathrm{~m}^{3}$ of wastewater is discharged directly to the Danube river every day. Screening analyses of the water within the Danube basin around city of Novi Sad included more than 300 different organic substances, while target analysis was conducted for all WFD pollutants. The methodology for generating the list of priority substances was applied for the first time in the Danubian region around the city of Novi Sad. By applying the prioritization procedure, 86 organic substances were determined in screening analyses and 27 substances obtained within target analyses were identified as the most relevant. In addition, seasonal variation analysis was conducted to determine the occurrence trends of specific compounds in different seasons.
\end{abstract}

Keywords: feco-toxicity, prioritization, screening and target analyses, water pollutants, water quality monitoring

\section{Introduction}

Water, as one of the most important parts of the environment, is essential for all living organisms.

*e-mail: majadjogo@uns.ac.rs
However, it can be easily contaminated and consequently represents a hazard. That is the reason why monitoring quality of water bodies has great importance.

In the European Union the Water Framework Directive (WFD), as the first joint legislation in this field, defines strategies against water pollution with the aim to achieve good (ecological and chemical) status of all water bodies within all member states and 
candidate countries. This legislation requires monitoring of priority and non-priority chemicals discharged in significant quantities [1].

Serbia has defined water quality monitoring parameters within its own Law on Water (Official Gazette of Republic of Serbia 30/10, 93/2012 and 101/2016). However, in the past, the monitoring was limited to physico-chemical parameters and analysis of inorganic compounds, while organics were completely neglected. Part of the legislation has been harmonized with EU legislation, but has so far not been fully implemented so far. Currently, monitoring the quality of surface water in Serbia is conducted by the Serbian Environmental Protection Agency (SEPA) and contains: (1) results of an examination of biological elements for evaluation of ecological status of surface water; (2) results of analysis of physico-chemical, chemical and microbiological parameters in surface water and groundwater; and (3) results of examination of the quality of sediment in rivers and accumulations. In 2015, the monitoring was enlarged and also included the majority of priority and priority-hazardous substances from 53 water bodies in Serbia. However, due to the technical limitations of the equipment and lack of expertise, we present analytical results on priority WFD substances, which in most of cases were below LOD and LOQ.

Additional monitoring of surface water for organic compounds in Serbia has been conducted through several international projects in past years. NATO Science for Peace Project ESP.EAP.SFPP 984087 included monitoring of wastewater, surface water and raw water used for production of drinking water in the City of Novi Sad, Serbia, 2012-2013. Obtained results from target [2] and non-target [3] analyses point out the presence of various organic compounds in aquatic matrices. Last Joint Danube Survey in 2013 [4, 5] monitored the quality of the Danube at 20 sampling locations in Serbia, including two locations upstream and downstream of Novi Sad.

On a national level there are several projects involving monitoring and analysis of organic compounds in water samples [6], however, they are mostly focused on certain types of industry [7] and agricultural activities. The results of other studies conducted in the Novi Sad region on caffeine and other emerging pollutants [8], pharmaceuticals [9], phthalates [10], OCPs [11] and other pollutants [12] point out on the need to define comprehensive and river-basin specific national monitoring programmes as well as to develop emergency response plans.

Even though, through non-target screening, information on various compounds can be obtained, it does not reveal information about the risk of these compounds to living organisms in surface water and consequently human health. This risk assessment is of significant importance, especially for Novi Sad, since the filtered surface water is used for the production of drinking water.
The prioritization techniques, as one of the effective ways for risk assessment, have evolved in the last 20 years, and since the adoption of the WFD it has become the obligatory procedure in the EU member states. Combined monitoring-based and modelling-based priority setting (COMMPS) procedure was the first European-wide prioritization exercise that resulted in the current list of priority substances [13].

The modelling-based approach did not allow for a quantitative assessment based on PEC/PNEC ratios [14]. A more recent study [15] has introduced a decision tree that first classifies chemicals into six categories, depending on the available information. The priority within each category is then evaluated based on the frequency of exceedance and the extent of exceedance of predicted no-effect concentrations (PNECs). These two indictors are based on maximum environmental concentrations (MEC) rather than the commonly used statistically based averages (predicted effect concentration, PEC).

The aim of this work was to determine the most relevant pollutants in Danube surface water that could represent a significant hazard for living organisms in surface water in the Novi Sad region, where untreated wastewater is directly discharged into the Danube in residential areas near the sources of raw water [16, 17]. In addition, the untreated landfill leachate from municipal landfill is indirectly discharged into the Danube surface water [18].

The prioritization approach was applied for the first time on target and non-target screening results from Serbia in order to develop a platform for selecting a river basin list of specific hazardous pollutants.

\section{Experimental Procedures}

\section{Selection of Sampling Locations}

Based on the location of the entire sewerage network in the City of Novi Sad, 9 sampling points have been selected for the campaigns. Four sites were located within municipal wastewater collectors (GC1', GC2', RO', RP'), including five in the Danube riverbed (RI, GC1", GC2', RO', RP'). Information and location of sampling sites are given in Table 1 and in Fig. 1. Sampling site RI is located upstream of Novi Sad, before all discharge points, and it has been selected in order to assess the eco toxicological status of the Danube prior to any local urban impact. Analysis of wastewater from the sewerage system determined the level of contamination of municipal and industrial wastewater streams, which are discharged directly into the Danube without any treatment. Danube surface water has been sampled $100 \mathrm{~m}$ downstream of each discharge in order to assess the impact of wastewater streams on eco toxicological status of the river. The sewage system at sampling site RO' is located in the area of the water supply source and downstream close to the industrial part of the city 
Table 1. GPS locations of sampling sites.

\begin{tabular}{|c|c|c|c|c|}
\hline No. & Location & Code & Northern latitude & Eastern longitude \\
\hline 1 & Cepelin & GC1" & $45^{\circ} 15^{\prime} 5.40 ’ \mathrm{~N}$ & $19^{\circ} 51^{\prime} 22.53$ ”E \\
\hline 2 & Beogradski kej & GC2" & $45^{\circ} 15^{\prime} 43.03^{\prime \prime} \mathrm{N}$ & 1951’27.09’"E \\
\hline 3 & Ratno ostrvo & $\mathrm{RO}^{\prime \prime}$ & $45^{\circ} 15^{\prime} 13.39^{\prime \prime} \mathrm{N}$ & $19^{\circ} 54 ’ 38.48^{\prime \prime} \mathrm{E}$ \\
\hline 4 & Rokov potok & $\mathrm{RP}^{\prime \prime}$ & $45^{\circ} 15^{\prime} 0.47^{\prime \prime} \mathrm{N}$ & 1954’11.33”Е \\
\hline 5 & Collector Cepelin & $\mathrm{GCl}^{\prime}$ & $45^{\circ} 15^{\prime} 3,704^{\prime \prime} \mathrm{N}$ & $19^{\circ} 51^{\prime} 18,329^{\prime \prime} \mathrm{E}$ \\
\hline 6 & Collector Beogradski kej & $\mathrm{GC}^{\prime}$ & $45^{\circ} 15^{\prime} 44.19^{\prime \prime} \mathrm{N}$ & $19^{\circ} 51{ }^{\prime} 22.16^{\prime \prime} \mathrm{E}$ \\
\hline 7 & Discharge Ratno ostrvo & $\mathrm{RO}^{\prime}$ & $45^{\circ} 15^{\prime} 22.95^{\prime \prime} \mathrm{N}$ & 1954’39.94’'Е \\
\hline 8 & Collector Rokov potok & $\mathrm{RP}^{\prime}$ & $45^{\circ} 14^{\prime} 56.65^{\prime \prime} \mathrm{N}$ & $19^{\circ} 53^{\prime} 43.673$ ”'E \\
\hline 9 & Ribarac & RI & $45^{\circ} 13^{\prime} 54.25^{\prime \prime} \mathrm{N}$ & $19^{\circ} 50^{\prime} 44.62 ” \mathrm{E}$ \\
\hline
\end{tabular}

with an Oil Refinery, thermoelectric and heat generating plant.

RP' is located on the other bank of the river in agricultural area and in the vicinity of a plant for production of diagnostic reagents, laboratory chemicals and solvents. Sampling sites GC1"' and GC2" are located on the stretch near or under three bridges, indicating the water runoff from the bridges as a possible source of Danube surface water pollution.

Sampling was scheduled during winter, summer and autumn in order to compare pollution during different seasons and connect them with typical agricultural, industrial and human activities.

\section{Description of Screening and Target} Analysis Methods

Stir bar sorptive extraction (SBSE) and liquid-toliquid extraction was applied for preparation of samples, while GC-TOF-MS was used for screening analyses. The extraction method and analytical approach are fully described in the paper by Milic et al. [3].

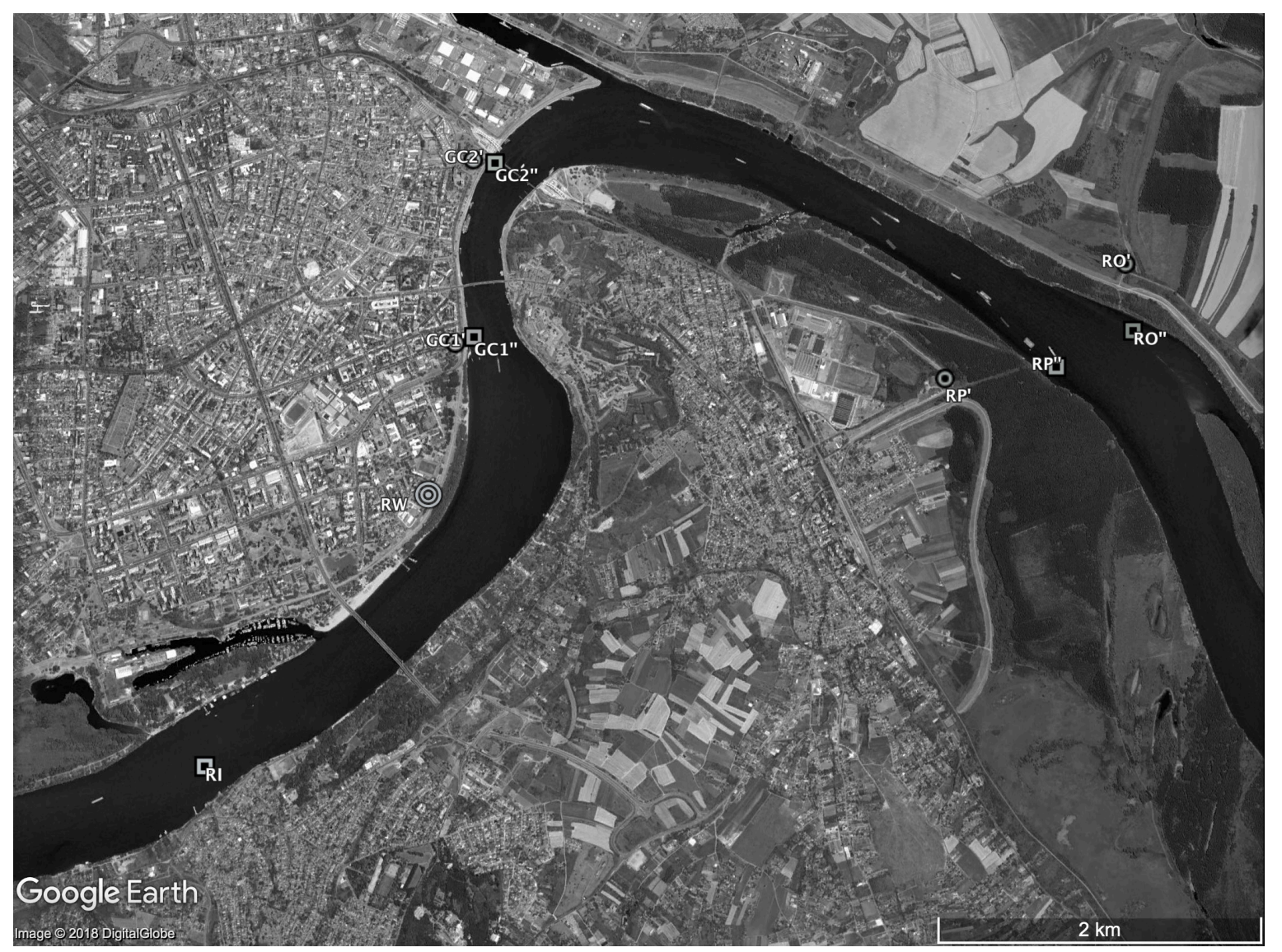

Fig. 1. Location of sampling sites within the city of Novi Sad. 
Miloradov and cooperates [2] explained that the procedures used for quantitative analyses of selected compounds (WFD pollutants - ISO 6468, VOCs - ISO 10301, tributyltin compounds - DIN EN 17025, and Simazine, Atrazine, Isoproturon, Diuron and hormones - modified ISO 11369).

\section{Quantification of Concentration Values from Screening Analysis}

The screening analysis was performed to identify as many pollutants in wastewater and surface water as possible, which would extend the list of the relevant pollutants for Novi Sad. The results obtained within the screening analysis were quantified by comparison of the signal of an unknown compound to the signal generated by the known concentration of an internal standard. This method provides only rough estimation of the actual concentration, but this error usually varies within one order of magnitude, which is well within the range of uncertainty associated with the eco-toxicological predictions.

\section{Determining Eco-Toxicity Values}

The quantitative structure-activity relationships (QSAR) approach was used to predict the toxicity of selected identified organic pollutants based on their chemical structure. In the classical approach, toxicity of compounds is expressed as the minimal concentration that is toxic for living organisms at three different trophic levels (e.g., with fish, algae and Daphnia magna). The QSAR approach is based on the prediction of critical effect concentrations (PNEC - predicted no-effect concentration). PNEC value represents the concentration predicted to cause no effect on an organism.

Around 300 compounds, identified from three screening and two target analyses, have been selected for eco-toxicity assessment. Determining PNEC values was conducted by renowned external company with significant experience in this field.

The most accurate were PNEC values already defined in the existing EU legislation: Directive 2011/876/EC, Directive 2008/105/EC and Water Framework Directive 2000/60/EC.

Compounds that do not have PNEC values defined in the legislation were identified in the ecotoxicity databases: AQUIRE and ETOX. Values for remaining compounds were determined using the QSAR approach.

\section{Prioritization Procedure}

For defining a list of major pollutants a prioritization approach was applied based on a comparison of the compounds' measured exposure levels, referred as predicted environmental concentration (PEC) and ecological safety threshold, or predicted no-effect concentration (PNEC) [19]. All compounds with the
PEC/PNEC risk ratio above 1 [20] were regarded as relevant and were ranked based on the ratio.

\section{Results and Discussion}

\section{Identifying Environmental Pressures}

Sampling campaigns of wastewater and Danube surface water in Novi Sad were conducted in winter, spring/summer and autumn periods. The distribution of sampling campaigns to different seasons should cover all industrial and domestic activities over the whole year. In winter, the most expected compounds were those coming from increased residential heating, incomplete combustion of oil, etc. In spring, summer and autumn the most commonly expected pollutants could be pesticides and fertilizers due to significant agricultural activity in this area [21] and the absence of a wastewater treatment plant and chemical compounds coming directly from household waste (e.g., cosmetics, fragrances, detergents, sun protection agents, washing powders, pharmaceuticals and the wide use of a large variety of products, etc.). Detection of alkanes was anticipated on localities downstream from the Novi Sad oil refinery. The destruction of the Novi Sad oil refinery during the 1999 NATO Campaign caused a spill of more than 70,000 tons of crude oil, of which more than 5,500 tons were discharged directly into the Danube. As a result, Danube sediment was heavily polluted with PAHs and other oil derivatives (UNEP report: The Kosovo Conflict, Consequences for the Environment and Human Settlements, 1999, ISBN 92-807-1801-1), and still represents one of the major sources of pollution of the surface water and a threat to the quality of raw water used for the production of drinking water.

\section{Prioritization Approach}

The screening analysis was conducted on all 34 samples. Phthalates, PAHs, glycols and derivatives, caffeine, bisphenol A, terpenes and fatty acids were the most frequently occurring compounds in the wastewater and the Danube surface water near the Novi Sad location. Dibutyl phthalate, diethyl phthalate, dioctyl phthalate, and bisphenol A which are on the NORMAN list of emerging substances and di(2-ethylhexyl) phthalate [22], which is on the list of WFD priority substances, were detected in all the examined samples [3]. Phthalates are used as plasticizers, industrial and lubricating oils, defoaming agents, cosmetics and insect repellents, thus indicating pollution of anthropogenic origin. Terpenes could occur in cosmetics, care products, and home cleaning products, and originate directly from household waste. The sources of the detected fatty acids in the aquatic media are mainly from degradation processes of petroleum hydrocarbons or animal and vegetable fats.

Based on the screening analysis results, 151 organic compounds were selected for the two target analyses of 
Table 2. List of compounds - screening analysis.

\begin{tabular}{|c|c|c|c|c|c|}
\hline InChIKey & CAS & $\begin{array}{l}\text { Compound name } \\
\text { / NIST library }\end{array}$ & $\begin{array}{c}\text { Lowest } \\
\text { PNEC ng/l }\end{array}$ & $\begin{array}{l}\text { Max con- } \\
\text { centration }\end{array}$ & $\mathrm{MC} / \mathrm{PNEC}$ \\
\hline BIADSXOKHZFLSN-RMCJHQKMSA-N & $473-03-0$ & Ambrein & 0,0000024 & 100,59 & 42802953,7 \\
\hline HMSWAIKSFDFLKN-UHFFFAOYSA-N & $630-01-3$ & Hexacosane & 0,00022 & 781,56 & 3627715,4 \\
\hline YKNWIILGEFFOPE-UHFFFAOYSA-N & $629-99-2$ & Pentacosane & 0,00054 & 956,51 & 1779488,1 \\
\hline POOSGDOYLQNASK-UHFFFAOYSA-N & $646-31-1$ & Tetracosane & 0,0013 & 662,10 & 494513,4 \\
\hline BJQWYEJQWHSSCJ-UHFFFAOYSA-N & $593-49-7$ & Heptacosane & 0,000086 & 38,16 & 442598,7 \\
\hline HOWGUJZVBDQJKV-UHFFFAOYSA-N & $629-97-0$ & Docosane & 0,0083 & 590,54 & 71455,4 \\
\hline OSJUENOXPFOHLF-UHFFFAOYSA-N & $6418-47-9$ & Heneicosane, 3-methyl- & 0,012 & 364,63 & 30312,9 \\
\hline CCXNGHAFWSFYNV-UHFFFAOYSA-N & $25117-37-7$ & Heneicosane, 5-methyl- & 0,012 & 208,55 & 17378,9 \\
\hline FNAZRRHPUDJQCJ-UHFFFAOYSA-N & $629-94-7$ & Heneicosane & 0,020 & 230,91 & 11280,1 \\
\hline KZJWDPNRJALLNS-FBZNIEFRSA-N & $83-47-6$ & Stigmast-5-en-3-ol & 0,059 & 402,05 & 6849,3 \\
\hline LQERIDTXQFOHKA-UHFFFAOYSA-N & $629-92-5$ & Nonadecane & 0,125 & 732,75 & 5869,0 \\
\hline RZJRJXONCZWCBN-UHFFFAOYSA-N & $593-45-3$ & Octadecane & 0,307 & 1227,21 & 3997,9 \\
\hline NHLUYCJZUXOUBX-UHFFFAOYSA-N & $27400-77-7$ & Nonadecene & 0,388 & 1222,93 & 3154,8 \\
\hline MLKZKPUBHSWMNA-UHFFFAOYSA-N & $1560-84-5$ & Eicosane, 2-methyl- & 0,122 & 338,25 & 2781,6 \\
\hline NYRRMADCQLTNBX-UHFFFAOYSA-N & $6418-45-7$ & Nonadecane, 3-methyl- & 0,297 & 437,10 & 1473,9 \\
\hline QIQXTHQIDYTFRH-UHFFFAOYSA-N & $57-11-4$ & Octadecanoic acid & 1,318 & 1094,29 & 830,2 \\
\hline HVYWMOMLDIMFJA-DPAQBDIFSA-N & $57-88-5$ & Cholesterol & 0,536 & 424,50 & 791,9 \\
\hline XUGNVMKQXJXZCD-UHFFFAOYSA-N & $142-91-6$ & Isopropyl palmitate & 2,520 & 1859,61 & 738,0 \\
\hline FHIVAFMUCKRCQO-UHFFFAOYSA-N & $333-41-5$ & Diazinone & 0,200 & 146,06 & 730,3 \\
\hline KZJWDPNRJALLNS-VJSFXXLFSA-N & $83-46-5$ & beta-Sitosterol & 0,059 & 40,14 & 683,8 \\
\hline NDJKXXJCMXVBJW-UHFFFAOYSA-N & $629-78-7$ & Heptadecane & 1,072 & 725,81 & 677,0 \\
\hline BFAGLVWBOUDHBS-UHFFFAOYSA-N & $54833-23-7$ & Eicosane, 10-methyl- & 0,128 & 54,55 & 425,9 \\
\hline BGHCVCJVXZWKCC-UHFFFAOYSA-N & $629-59-4$ & Tetradecane & 2,913 & 1096,47 & 376,4 \\
\hline ULBTUVJTXULMLP-UHFFFAOYSA-N & $123-95-5$ & Octadecanoic acid, butyl ester & 0,210 & 74,63 & 355,4 \\
\hline IPCSVZSSVZVIGE-UHFFFAOYSA-N & $57-10-3$ & Hexadecanoic acid & 9,622 & 3273,90 & 340,2 \\
\hline YCOZIPAWZNQLMR-UHFFFAOYSA-N & $629-62-9$ & Pentadecane & 1,550 & 425,89 & 274,8 \\
\hline ADOBXTDBFNCOBN-UHFFFAOYSA-N & $6765-39-5$ & Heptadecene & 1,977 & 420,11 & 212,5 \\
\hline ZQPPMHVWECSIRJ-KTKRTIGZSA-N & $112-80-1$ & 9-octadecenoic acid & 17,636 & 3317,34 & 188,1 \\
\hline CCCMONHAUSKTEQ-UHFFFAOYSA-N & $112-88-9$ & Octadecene & 0,867 & 131,15 & 151,3 \\
\hline OYHQOLUKZRVURQ-HZJYTTRNSA-N & $60-33-3$ & 9,12-octadecadienoic acid & 24,692 & 3713,77 & 150,4 \\
\hline DCAYPVUWAIABOU-UHFFFAOYSA-N & $544-76-3$ & Hexadecane & 8,100 & 1160,33 & 143,3 \\
\hline PESKGJQREUXSRR-JDIFZLMISA-N & $601-53-6$ & Cholestan-3-one & 4,243 & 436,49 & 102,9 \\
\hline QYIXCDOBOSTCEI-QCYZZNICSA-N & $80-97-7$ & Cholestanol & 12,260 & 1215,18 & 99,1 \\
\hline HPDKJRSKBCPMIY-UHFFFAOYSA-N & $6418-44-6$ & Heptadecane, 3-methyl- & 1,578 & 155,83 & 98,7 \\
\hline GLYJVQDYLFAUFC-UHFFFAOYSA-N & $111-06-8$ & Hexadecanoic acid, butyl ester & 0,738 & 66,82 & 90,5 \\
\hline VLPFTAMPNXLGLX-UHFFFAOYSA-N & $538-23-8$ & Glycerol tricaprylate & 1,323 & 111,51 & 84,3 \\
\hline LGJMUZUPVCAVPU-KZXGMYDKSA-N & $19466-47-8$ & Stigmastanol & 3,156 & 251,97 & 79,8 \\
\hline RYYVLZVUVIJVGH-UHFFFAOYSA-N & $58-08-2$ & Caffeine & 100,000 & 4600,14 & 46,0 \\
\hline
\end{tabular}


Table 2. Continued.

\begin{tabular}{|c|c|c|c|c|c|}
\hline ORFWYUFLWUWSFM-UHFFFAOYSA-N & $646-13-9$ & $\begin{array}{l}\text { Octadecanoic acid, 2-methyl- } \\
\text { propyl ester }\end{array}$ & 0,356 & 15,63 & 43,9 \\
\hline YYELLDKEOUKVIQ-UHFFFAOYSA-N & $3055-98-9$ & $\begin{array}{l}\text { Octaethylene glycol monodo- } \\
\text { decyl ether }\end{array}$ & 32,227 & 1130,50 & 35,1 \\
\hline TUNFSRHWOTWDNC-UHFFFAOYSA-N & $544-63-8$ & Tetradecanoic acid & 69,405 & 2057,13 & 29,7 \\
\hline HFDVRLIODXPAHB-UHFFFAOYSA-N & $1120-36-1$ & 1-tetradecene & 22,873 & 494,59 & 21,6 \\
\hline WWPCLIMUTNKTDY-UHFFFAOYSA-N & $6418-43-5$ & Hexadecane, 3-methyl- & 3,678 & 75,94 & 20,7 \\
\hline NQAVPKIJZCHUNS-UHFFFAOYSA-N & $1795-18-2$ & Cyclohexane, tetradecyl- & 0,778 & 13,89 & 17,9 \\
\hline BOTWFXYSPFMFNR-PYDDKJGSSA-N & $150-86-7$ & Phytol & 7,061 & 112,95 & 16,0 \\
\hline IZWSFJTYBVKZNK-UHFFFAOYSA-N & $14933-08-5$ & $\begin{array}{l}\text { 3-(N,N-dimethyllaurylammo- } \\
\text { nio)propanesulfonate }\end{array}$ & 381,210 & 5718,55 & 15,0 \\
\hline SECPZKHBENQXJG-FPLPWBNLSA-N & $373-49-9$ & 9-hexadecenoic acid & 93,829 & 1274,56 & 13,6 \\
\hline FLIACVVOZYBSBS-UHFFFAOYSA-N & $112-39-0$ & $\begin{array}{l}\text { Hexadecanoic acid, methyl } \\
\text { ester }\end{array}$ & 11,611 & 154,81 & 13,3 \\
\hline HPEUJPJOZXNMSJ-UHFFFAOYSA-N & $112-61-8$ & $\begin{array}{c}\text { Octadecanoic acid, methyl } \\
\text { ester }\end{array}$ & 1,830 & 18,79 & 10,3 \\
\hline OJIBJRXMHVZPLV-UHFFFAOYSA-N & $110-34-9$ & $\begin{array}{l}\text { Hexadecanoic acid, 2-methyl- } \\
\text { propyl ester }\end{array}$ & 1,900 & 19,38 & 10,2 \\
\hline LAPRIVJANDLWOK-UHFFFAOYSA-N & $3055-95-6$ & $\begin{array}{l}\text { Pentaethylene glycol monodo- } \\
\text { decyl ether }\end{array}$ & 164,980 & 1477,17 & 8,9 \\
\hline SNRUBQQJIBEYMU-UHFFFAOYSA-N & $112-40-3$ & Dodecane & 25,564 & 211,53 & 8,3 \\
\hline NKJOXAZJBOMXID-UHFFFAOYSA-N & $629-82-3$ & Octane, 1,1'-oxybis- & 19,440 & 158,87 & 8,2 \\
\hline SIKJAQJRHWYJAI-UHFFFAOYSA-N & $120-72-9$ & 1h-indole & 1000,000 & 7153,71 & 7,2 \\
\hline VCHDBLPQYJAQSQ-KYJUHHDHSA-N & 27554-26-3 & $\begin{array}{l}\text { 1,2-benzenedicarboxylic acid, } \\
\text { diisooctyl ester }\end{array}$ & 140,000 & 878,56 & 6,3 \\
\hline $\begin{array}{l}\text { ARYTXMNEANMLMU-OZEQXKMUSA- } \\
\mathrm{N}\end{array}$ & $6538-02-9$ & Ergostanol & 5,622 & 33,33 & 5,9 \\
\hline JGMYDQCXGIMHLL-WAYWQWQTSA-N & $2416-20-8$ & Hexadecenoic acid, (11)- & 160,010 & 821,70 & 5,1 \\
\hline POULHZVOKOAJMA-UHFFFAOYSA-N & $143-07-7$ & Dodecanoic acid & 1339,800 & 6606,79 & 4,9 \\
\hline WPMWEFXCIYCJSA-UHFFFAOYSA-N & $5274-68-0$ & $\begin{array}{l}\text { Tetraethylene glycol monodo- } \\
\text { decyl ether }\end{array}$ & 293,200 & 1406,21 & 4,8 \\
\hline IIYFAKIEWZDVMP-UHFFFAOYSA-N & $629-50-5$ & Tridecane & 27,839 & 122,06 & 4,4 \\
\hline NYOXRYYXRWJDKP-GYKMGIIDSA-N & $601-57-0$ & Cholest-4-en-3-one & 5,153 & 21,80 & 4,2 \\
\hline BTFJIXJJCSYFAL-UHFFFAOYSA-N & $629-96-9$ & 1-eicosanol & 0,992 & 3,91 & 3,9 \\
\hline JWMFYGXQPXQEEM-GCOKGBOCSA-N & $641-85-0$ & Allopregnane & 3,000 & 11,69 & 3,9 \\
\hline AFFLGGQVNFXPEV-UHFFFAOYSA-N & $872-05-9$ & 1-decene & 558,300 & 2158,58 & 3,9 \\
\hline LEACJMVNYZDSKR-UHFFFAOYSA-N & $5333-42-6$ & 1-dodecanol, 2-octyl- & 1,675 & 6,28 & 3,8 \\
\hline NEHDRDVHPTWWFG-UHFFFAOYSA-N & $123-79-5$ & Hexanedioic acid, dioctyl ester & 4,290 & 14,78 & 3,4 \\
\hline BOTWFXYSPFMFNR-HMMYKYKNSA-N & $102608-53-7$ & $\begin{array}{l}\text { 3,7,11,15-tetramethyl-2-hexa- } \\
\text { decen-1-ol }\end{array}$ & 7,060 & 23,39 & 3,3 \\
\hline JXNPEDYJTDQORS-UHFFFAOYSA-N & $1577-52-2$ & 9,12-octadecadien-1-ol & 10,818 & 30,10 & 2,8 \\
\hline GHVNFZFCNZKVNT-UHFFFAOYSA-N & $334-48-5$ & Decanoic acid & 2188,800 & 5336,87 & 2,4 \\
\hline DOIRQSBPFJWKBE-UHFFFAOYSA-N & $84-74-2$ & $\begin{array}{c}\text { 1,2-benzenedicarboxylic acid, } \\
\text { dibutyl ester }\end{array}$ & 600,000 & 1267,81 & 2,1 \\
\hline YNPNZTXNASCQKK-UHFFFAOYSA-N & $85-01-8$ & Phenanthrene & 30,000 & 62,61 & 2,1 \\
\hline FKMHSNTVILORFA-UHFFFAOYSA-N & $3055-94-5$ & $\begin{array}{l}\text { Triethylene glycol monodo- } \\
\text { decyl ether }\end{array}$ & 553,650 & 1150,44 & 2,1 \\
\hline
\end{tabular}


Table 2. Continued.

\begin{tabular}{|c|c|c|c|c|c|}
\hline DWHIUNMOTRUVPG-UHFFFAOYSA-N & $3055-97-8$ & $\begin{array}{l}\text { Heptaethylene glycol mono- } \\
\text { dodecyl ether }\end{array}$ & 71,998 & 146,76 & 2,0 \\
\hline KSEZPRJUTHMFGZ-UHFFFAOYSA-N & $88-29-9$ & $\begin{array}{l}\text { 7-acetyl-6-ethyl-1,1,4,4- } \\
\text { tetramethyl tetralin }\end{array}$ & 514,010 & 1023,74 & 2,0 \\
\hline AXISYYRBXTVTFY-UHFFFAOYSA-N & $110-27-0$ & $\begin{array}{c}\text { Tetradecanoic acid, 1-methyl- } \\
\text { ethyl ester }\end{array}$ & 20,621 & 36,83 & 1,8 \\
\hline CSHWQDPOILHKBI-UHFFFAOYSA-N & $198-55-0$ & Perylene & 24,510 & 40,80 & 1,7 \\
\hline AAOYEEWVNUXGDK-UHFFFAOYSA-N & $3208-26-2$ & 9-phenyl-1-nonanol & 259,680 & 430,33 & 1,7 \\
\hline YQLRKXVEALTVCZ-UHFFFAOYSA-N & $28556-81-2$ & 2,6-dimethylphenyl isocyanate & 2215,400 & 3076,65 & 1,4 \\
\hline MGLDCXPLYOWQRP-UHFFFAOYSA-N & $1191-85-1$ & $\begin{array}{c}\text { 5,8,11,14-eicosatetraynoic } \\
\text { acid }\end{array}$ & 84,667 & 116,69 & 1,4 \\
\hline UIKROCXWUNQSPJ-VIFPVBQESA-N & $486-56-6$ & $\begin{array}{l}\text { 2-pyrrolidinone, 1-methyl-5- } \\
\text { (3-pyridinyl)- }\end{array}$ & 660,320 & 907,02 & 1,4 \\
\hline VQOXUMQBYILCKR-UHFFFAOYSA-N & $2437-56-1$ & 1-tridecene & 52,886 & 60,47 & 1,1 \\
\hline TXVHTIQJNYSSKO-UHFFFAOYSA-N & $192-97-2$ & Benzo[e]pyrene & 17,974 & 20,47 & 1,1 \\
\hline ZTMZUYHXZPUDRF-UHFFFAOYSA-N & $82304-66-3$ & $\begin{array}{l}\text { 7,9-di-tert-butyl-1-oxaspi- } \\
\text { ro[4.5]deca-6,9-diene-2,8- } \\
\text { dione }\end{array}$ & 365,680 & 416,11 & 1,1 \\
\hline HHZIOLLKZWLCOX-MDZDMXLPSA-N & $13481-95-3$ & $\begin{array}{c}\text { 10-octadecenoic acid, methyl } \\
\text { ester }\end{array}$ & 8,860 & 9,79 & 1,1 \\
\hline LLEMOWNGBBNAJR-UHFFFAOYSA-N & $90-43-7$ & [1,1'-biphenyl]-2-ol & 360,000 & 389,82 & 1,1 \\
\hline BGRWYDHXPHLNKA-UHFFFAOYSA-N & $10543-57-4$ & $\begin{array}{c}\mathrm{N}, \mathrm{N}, \mathrm{N}^{\prime}, \mathrm{N}^{\prime} \text {-tetraacetylethylen- } \\
\text { ediamine }\end{array}$ & 1294,800 & 1397,06 & 1,1 \\
\hline
\end{tabular}

the wastewater and surface water samples. The obtained results indicate that the attention should focus on priority pollutants such as octylphenols, di-(ethylhexyl)phthalate, DDT, endosulfan, dieldrin, endrin, and some heavy toxic metal ions. Concentration levels of all selected compounds exceeded proposed annual average environmental quality standard (AA EQS) values [2]. Octylphenols are commercially added to a number of products (paints, adhesives, plastics and cosmetics), and thus their presence in water samples indicates pollution from household waste.

The results of both quantified screening and target analysis, as well as eco-toxicity data for detected compounds, were used in order to compile the list of the most relevant pollutants for Novi Sad. The prioritization approach based on the occurrence and predicted toxicity data has been applied. The main decision criterium was the exceedance of predicted no-effect concentrations (PNEC) for all organic compounds monitored in the wastewater and surface water samples. Values below LoQ were not included in the prioritization approach. The indicator for ranking of compounds shows the exceedance of the compound's concentration respective to the corresponding PNEC value. It was obtained through the ratio of maximum concentration (MC) and the PNEC value of each analyzed compound. The $\mathrm{MC} / \mathrm{PNEC}$ ratio was used to rank the compounds. Only pollutants with a ratio above 1 were considered. Obtained PNEC values relate only to surface water compounds and may be applied to wastewater pollutants if the dilution factor is applied. Since this research had only three sampling campaigns, and therefore an insufficient number of samples, the dilution factor for wastewater compounds has been disregarded since it would lead to the elimination of certain pollutants that might be relevant in the future.

\section{The Selection of Relevant Pollutants from Screening and Target Analyses}

Table 2 shows the list of the compounds observed within three screening analyses on 11 locations in the samples of wastewater and Danube surface water and ranks the compounds according to the exceedance of lowest PNEC. Additionally, Table 3 presents the ranked list of compounds detected in two screening analyses in Novi Sad.

Only relevant pollutants with the $\mathrm{MC} / \mathrm{PNEC}$ ratio above 1 are presented in both tables.

Tables 2 and 3 show that the most hazardous group of compounds in the Novi Sad are linear and branched alkanes, which is not surprising due to the vicinity of the oil refinery. Other important groups of compounds include hormones, pesticides (Heptachlor, DDT and DDD), industrial chemicals, and PAHs. The presence of pesticides indicates pollution from agricultural activities, households and farms in the vicinity of the Danube surface water. PAHs, primarily generated from 
Table 3. List of compounds - target analysis.

\begin{tabular}{|c|c|c|c|c|c|}
\hline InChIKey & CAS & $\begin{array}{c}\text { Compound name / NIST } \\
\text { library }\end{array}$ & $\begin{array}{c}\text { Lowest } \\
\text { PNEC } \\
\text { ng/l }\end{array}$ & $\begin{array}{l}\text { Max concen- } \\
\text { tration }\end{array}$ & $\mathrm{MC} / \mathrm{PNEC}$ \\
\hline FRCCEHPWNOQAEU-UHFFFAOYSA-N & $76-44-8$ & Heptachlor & 0,0002 & 420 & 2100000,0 \\
\hline ZXFXBSWRVIQKOD-UHFFFAOYSA-N & $1024-57-3$ & Heptachlor epoxide & 0,0002 & 50 & 250000,0 \\
\hline DXBHBZVCASKNBY-UHFFFAOYSA-N & $56-55-3$ & Benz(a)anthracene & 1,8 & 210 & 116,7 \\
\hline GVEPBJHOBDJJJI-UHFFFAOYSA-N & $206-44-0$ & Fluoranthene & 6,3 & 510 & 81,0 \\
\hline YVGGHNCTFXOJCH-UHFFFAOYSA-N & $50-29-3$ & DDT-4,4' & 10 & 500 & 50,0 \\
\hline RDYMFSUJUZBWLH-UHFFFAOYSA-N & $115-29-7$ & Endosulfan-alpha & 5 & 230 & 46,0 \\
\hline OTMOUPHCTWPNSL-UHFFFAOYSA-N & $5598-15-2$ & Chlorpyrifos & 1 & 40 & 40,0 \\
\hline DFBKLUNHFCTMDC-PICURKEMSA-N & $60-57-1$ & Dieldrin & 10 & 270 & 27,0 \\
\hline AHJKRLASYNVKDZ-UHFFFAOYSA-N & $72-54-8$ & DDD-4,4' & 25 & 620 & 24,8 \\
\hline BBEAQIROQSPTKN-UHFFFAOYSA-N & $129-00-0$ & Pyrene & 20 & 490 & 24,5 \\
\hline YNPNZTXNASCQKK-UHFFFAOYSA-N & $85-01-8$ & Phenanthrene & 30 & 360 & 12,0 \\
\hline DTMRKGRREZAYAP-UHFFFAOYSA-N & $35694-08-7$ & PCB-194 & 0,2 & 1,2 & 6,0 \\
\hline JLYXXMFPNIAWKQ-GNIYUCBRSA-N & $58-89-9$ & $\begin{array}{l}\text { Hexachlorocyclohexane- } \\
\text { gamma }\end{array}$ & 5,5 & 30 & 5,5 \\
\hline NTDQQZYCCIDJRK-UHFFFAOYSA-N & $1806-26-4$ & Octylphenol & 100 & 540 & 5,4 \\
\hline CKAPSXZOOQJIBF-UHFFFAOYSA-N & $118-74-1$ & Hexachlorobenzene & 10 & 50 & 5,0 \\
\hline UCNVFOCBFJOQAL-UHFFFAOYSA-N & $72-55-9$ & DDE-4,4' & 25 & 110 & 4,4 \\
\hline HEDRZPFGACZZDS-UHFFFAOYSA-N & $67-66-3$ & Trichloromethane & 2500 & 9720 & 3,9 \\
\hline SNQQPOLDUKLAAF-UHFFFAOYSA-N & $84852-15-3$ & Nonylphenol & 300 & 1150 & 3,8 \\
\hline IGFHQQFPSIBGKE-UHFFFAOYSA-N & $104-40-5$ & 4-nonylphenol & 300 & 1140 & 3,8 \\
\hline DOIRQSBPFJWKBE-UHFFFAOYSA-N & $84-74-2$ & $\begin{array}{l}\text { 1,2-benzenedicarboxylic } \\
\text { acid, dibutyl ester }\end{array}$ & 600 & 2150 & 3,6 \\
\hline MWPLVEDNUUSJAV-UHFFFAOYSA-N & $120-12-7$ & Anthracene & 100 & 280 & 2,8 \\
\hline BJQHLKABXJIVAM-UHFFFAOYSA-N & $117-81-7$ & $\begin{array}{l}\text { Di(2-ethylhexyl)phthalate } \\
\text { (DEHP) }\end{array}$ & 1300 & 2630 & 2,0 \\
\hline NIHNNTQXNPWCJQ-UHFFFAOYSA-N & $86-73-7$ & Fluorene & 100 & 140 & 1,4 \\
\hline WDECIBYCCFPHNR-UHFFFAOYSA-N & 218-01-9 & Chrysene & 100 & 130 & 1,3 \\
\hline ISAVYTVYFVQUDY-UHFFFAOYSA-N & $140-66-9$ & $\begin{array}{l}\text { 4-(1,1,3,3-tetramethylbutyl)- } \\
\text { phenol }\end{array}$ & 100 & 110 & 1,1 \\
\hline YXFVVABEGXRONW-UHFFFAOYSA-N & $108-88-3$ & Toluene & 4300 & 4410 & 1,0 \\
\hline ZSDSQXJSNMTJDA-UHFFFAOYSA-N & $1582-09-8$ & Trifluralin & 30 & 30 & 1,0 \\
\hline
\end{tabular}

combustion processes, could be transported by wind from the thermal plant, oil refinery and small farms and through atmospheric deposition processes end up in surface water.

The highest exceedance of PNEC for compounds detected in screening analyses, was obtained for Ambrein, as the result of its very low value of PNEC (2.35E-6 ng/l), even though it was detected only in one wastewater sample in the concentration of $100.59 \mathrm{ng} / \mathrm{l}$. Ambrein is a fragrant substance used in the perfume industry. It was not detected in Danube surface water due to its low concentration level at the discharge and the dilution factor. Stigmast-5-en-3-ol is one of several phytosterols (plant sterols) with the basic cholestane structure. Phytosterols are isolated from vegetable oils or from by-product of wood pulp manufacture. A high extent of exceedance of almost 7000 was observed, since Stigmast-5-en-3-ol was detected in high concentrations in four wastewater samples. It was not detected in Danube surface water due to biological degradation processes and the dilution factor. Diazinone is a nonsystemic organophosphate insecticide currently 
Table 4. List of compounds in terms of seasonal variation - screening analyses.

\begin{tabular}{|c|c|c|c|c|c|}
\hline Compound name & $\begin{array}{c}\text { Winter } \\
\text { Max ratio }\end{array}$ & Compound name & $\begin{array}{l}\text { Summer } \\
\text { Max ratio }\end{array}$ & Compound name & $\begin{array}{l}\text { Autumn } \\
\text { Max ratio }\end{array}$ \\
\hline Ambrein & 42802954 & Hexacosane & 3627715 & Heptacosane & 442599 \\
\hline Stigmast-5-en-3-ol & 6849 & Pentacosane & 1779488 & Hexacosane & 337665 \\
\hline Octadecanoic acid & 830 & Tetracosane & 494513 & Pentacosane & 205682 \\
\hline Cholesterol & 792 & Docosane & 71455 & Tetracosane & 134916 \\
\hline Diazinone & 730 & $\begin{array}{l}\text { Heneicosane, 3-me- } \\
\text { thyl- }\end{array}$ & 30313 & Docosane & 26203 \\
\hline beta-Sitosterol & 684 & $\begin{array}{l}\text { Heneicosane, 5-me- } \\
\text { thyl- }\end{array}$ & 17379 & Heneicosane & 9230 \\
\hline Hexadecanoic acid & 340 & Heneicosane & 11280 & Heneicosane, 3-methyl- & 1867 \\
\hline Pentadecane & 243 & Nonadecane & 5869 & Nonadecane & 505 \\
\hline 9-octadecenoic acid & 188 & Octadecane & 3998 & Eicosane, 10-methyl- & 426 \\
\hline 9,12-octadecadienoic acid & 150 & Nonadecene & 3155 & Eicosane, 2-methyl- & 154 \\
\hline Cholestan-3-one & 103 & Eicosane, 2-methyl- & 2782 & Octadecane & 110 \\
\hline Cholestanol & 99 & $\begin{array}{l}\text { Nonadecane, 3-me- } \\
\text { thyl- }\end{array}$ & 1474 & Heptadecane & 20 \\
\hline Stigmastanol & 80 & Stigmast-5-en-3-ol & 771 & $\begin{array}{l}\text { Cyclohexane, tetrade- } \\
\text { cyl- }\end{array}$ & 18 \\
\hline Heptadecane & 65 & Isopropyl palmitate & 738 & Octadecanoic acid & 16 \\
\hline Hexadecane & 47 & Heptadecane & 677 & Nonadecane, 3-methyl- & 12 \\
\hline Caffeine & 46 & Tetradecane & 376 & Hexadecanoic acid & 5 \\
\hline Octaethylene glycol monododecyl ether & 35 & $\begin{array}{l}\text { Octadecanoic acid, } \\
\text { butyl ester }\end{array}$ & 355 & 1-eicosanol & 4 \\
\hline Tetradecanoic acid & 30 & Pentadecane & 275 & Allopregnane & 4 \\
\hline $\begin{array}{l}\text { 3-(N,N-dimethyllaurylammonio) } \\
\text { propanesulfonate }\end{array}$ & 15 & Heptadecene & 213 & 1-dodecanol, 2-octyl- & 4 \\
\hline 9-hexadecenoic acid & 14 & Octadecene & 151 & $\begin{array}{l}\text { Hexanedioic acid, } \\
\text { dioctyl ester }\end{array}$ & 3 \\
\hline Isopropyl palmitate & 13 & Hexadecane & 143 & Pentadecane & 3 \\
\hline Octadecanoic acid, methyl ester & 10 & Cholesterol & 128 & 9-octadecenoic acid & 2 \\
\hline Pentaethylene glycol monododecyl ether & 9 & $\begin{array}{l}\text { Heptadecane, 3-me- } \\
\text { thyl- }\end{array}$ & 99 & Hexadecane & 2 \\
\hline 1h-indole & 7 & $\begin{array}{l}\text { Hexadecanoic acid, } \\
\text { butyl ester }\end{array}$ & 91 & & \\
\hline Ergostanol & 6 & Glycerol tricaprylate & 84 & & \\
\hline Tetradecane & 5 & $\begin{array}{l}\text { Octadecanoic acid, } \\
\text { 2-methylpropyl ester }\end{array}$ & 44 & & \\
\hline Hexadecenoic acid, (11)- & 5 & 1-tetradecene & 22 & & \\
\hline Dodecanoic acid & 5 & $\begin{array}{l}\text { Hexadecane, 3-me- } \\
\text { thyl- }\end{array}$ & 21 & & \\
\hline Tetraethylene glycol monododecyl ether & 5 & Phytol & 16 & & \\
\hline Cholest-4-en-3-one & 4 & $\begin{array}{l}\text { Hexadecanoic acid, } \\
\text { methyl ester }\end{array}$ & 13 & & \\
\hline 1-decene & 4 & $\begin{array}{l}\text { Hexadecanoic acid, } \\
\text { 2-methylpropyl ester }\end{array}$ & 10 & & \\
\hline $\begin{array}{l}\text { 1,2-benzenedicarboxylic acid, di- } \\
\text { isooctyl ester }\end{array}$ & 3 & Dodecane & 8 & & \\
\hline
\end{tabular}


Table 4. Continued.

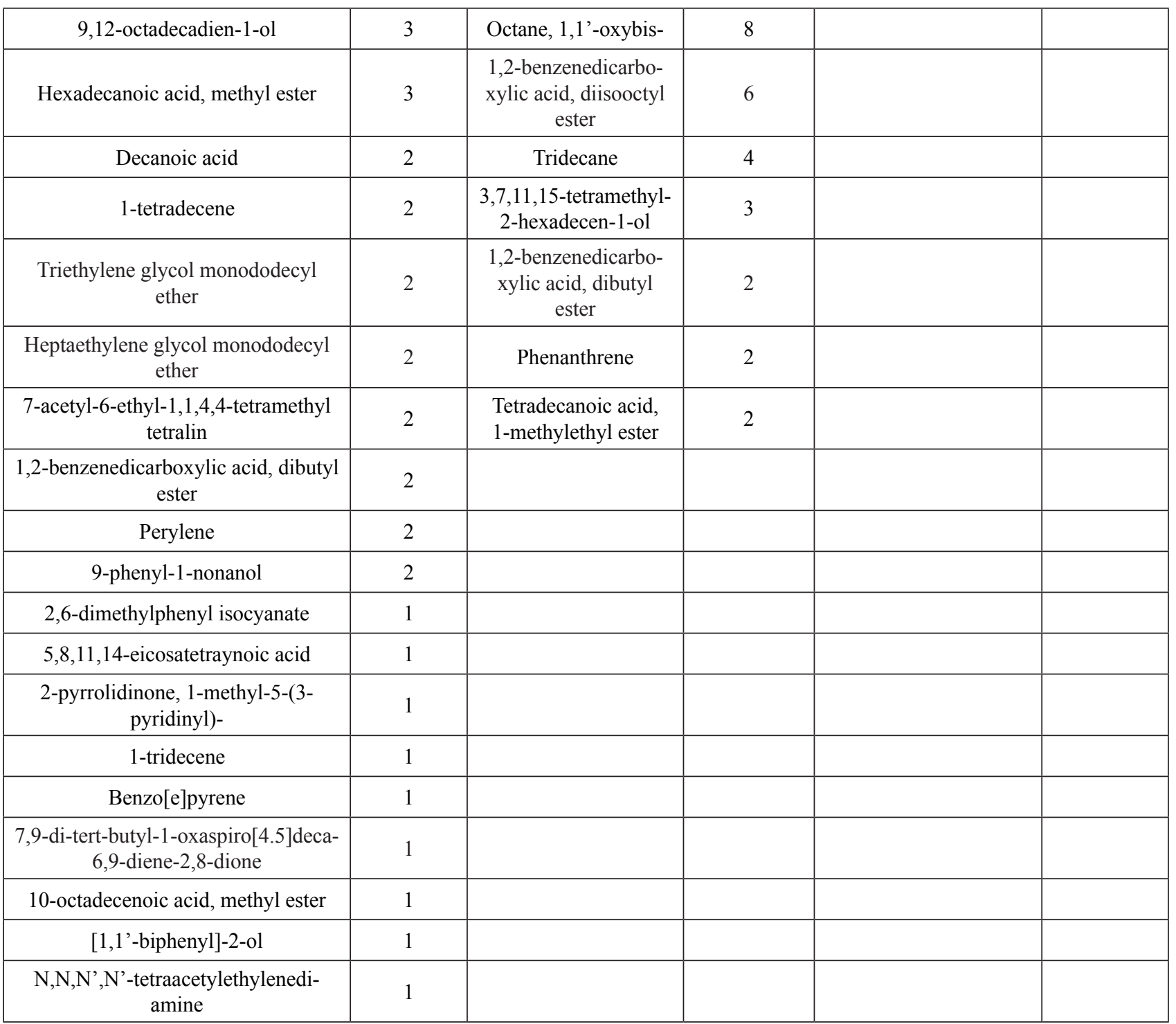

used in agriculture due to the ban of DDT. It was detected in wastewater samples with the maximum concentration of $146.06 \mathrm{ng} / \mathrm{l}$. Diazinone is relatively stable under standard ambient temperature and pressure. As a consequence, it was not detected in Danube water samples even though its exceedance of PNEC is very high. Benzo(a)anthracene and Fluoranthene, belonging to the group of PAHs, have similar values of MC/PNEC ratio, and were only detected in wastewater samples. Due to their low solubility in water and high potential to sorb sediments, their concentration levels in Danube surface water were very low. Other compounds such as: Cholestan-3one, Stigmastanol, Dodecane, and others, which were detected only in wastewater samples collected at discharges, have much smaller MC/PNEC ratios. Due to the dilution factor, they were not measured in Danube surface water samples. Compounds with high exceedance detected only in Danube surface water samples, such as Heptachlor epoxide, Octadecene and
Chlorpyrifos, occurred in water due to several factors: upstream Danubian countries, soil runoff, atmospheric deposition, and chemical reactions in aquatic environment.

Within the target analyses, MC of 27 organic compounds exceeded the predicted no effect concentrations (PNEC). The highest exceedance (2.100.000 times) was noted for Heptachlor, a commonly used insecticide, and consequently Heptachlor epoxide (250.000 times), which is a degradation product of Heptachlor formed by plants, animals and even humans after exposure to Hepatchlor. The third most relevant pollutant by target analyses is Benz(a)anthracene, with the MC/PNEC ratio of 116,67. MC of Fluorene and Anthracene were 1.4 and 2.8 times higher than PNEC of $0.1 \mu \mathrm{g} / \mathrm{L}$. The value of PNEC for Phenantrene is $0.03 \mu \mathrm{g} / \mathrm{L}$ and $\mathrm{MC}$ is 12 times higher than PNEC, while for fluoranthene PNEC of $0.0063 \mu \mathrm{g} / \mathrm{L}$ was 81 times lower than MC. All above-mentioned PAHs were detected at 3 of 11 sampling sites. Dibutylphthalate 
Table 5. List of compounds in terms of seasonal variation - target analyses.

\begin{tabular}{|c|c|c|c|}
\hline Compound & Max ratio Summer & Compound & Max ratio Autumn \\
\hline Heptachlor & 2100000 & Benzo(a)anthracene & 117 \\
\hline Heptachlor epoxide & 250000 & Fluoranthene & 25 \\
\hline DDT-4,4 & 50 & Pyrene & 12 \\
\hline Endosulfan-alpha & 46 & Phenanthrene & 5 \\
\hline Chlorpyrifos & 40 & Octylphenol & 5 \\
\hline Dieldrin & 27 & Pentachlorobenzene & 4 \\
\hline DDD-4,4 & 25 & Trichloromethane & 4 \\
\hline PCB-194 & 6 & Nonylphenol & 4 \\
\hline Pentachlorobenzene & 6 & 4,2-benzenedicarboxylic acid, dibutyl ester & \\
\hline Hexachlorocyclohexane-gamma & 5 & Anthracene & 5 \\
\hline Hexachlorobenzene & 5 & Di(2-ethylhexyl)phthalate (DEHP) & 1 \\
\hline DDE-4,4 & 4 & Fluorene & 1 \\
\hline Di(2-ethylhexyl)phthalate (DEHP) & 2 & Chrysene & 1 \\
\hline Phenanthrene & 1 & Toluene & $1,3,3$-tetramethylbutyl)-phenol \\
\hline
\end{tabular}

was detected in all 11 samples above PNEC of $0.6 \mu \mathrm{g} / \mathrm{L}$, while $\mathrm{MC}$ was 3.6 times higher than PNEC. The value of PNEC for DEHP is $1.3 \mu \mathrm{g} / \mathrm{L}$, which is 2 times lower than MC. Nonylphenols were detected at all sampling sites above PNEC of $0.021 \mu \mathrm{g} / \mathrm{L}$. MC of octylphenols was 5.4 higher than PNEC $(0.1 \mu \mathrm{g} / \mathrm{L})$. For (4-(1,1',3,3'-tetramethylbutyl)-phenol environmental concentration exceeded PNEC of $0.1 \mu \mathrm{g} / \mathrm{L}$ in only one water sample. Nonylphenols are produced in large volumes, and used in consumer laundry detergents, latex paints and lawn care products, thus they could originate from the household waste.

\section{Seasonal Variation of Relevant Substances}

The effects of climate change and different conditions in different seasons, such as temperature and precipitation, can have a significant effect on surface water quality. The increase of temperature can boost chemical reactions, while precipitation invokes surface runoff, thus increasing the concentration of a number of pollutants in water, such as pesticides, various microorganisms, etc. Since during the sampling campaigns the only difference in temperature was noted, it was not possible to take into consideration the impact of precipitation on the concentration levels of pollutants.

Tables 4 and 5 rank the pollutants observed within the screening and target analyses according to the season when they were detected (winter, summer and autumn). For all compounds presented in the following tables, CAS and InChIKey can be found in Tables 2 and 3.

Screening analysis results for summer and autumn seasons show increased concentration levels of alkanes (especially Hexacosane, Heptacosane, Pentacosane, Tetracosane, Docosane, Heneicosane, etc), possibly as a consequence of oil refinery activities in the part of the Danube prior to RP' and Sever IV' discharge locations. With the exception of Pentadecane, Heptadecane and Hexadecane (which are present in all seasons), in winter period alkanes were not detected in high concentrations in examined samples, unlike summer and autumn, most probably due to lower solubility in cold water. Significant compounds in winter include the following hormones with very high concentration levels: Stigamast-5-en-3-ol, Cholesterol, beta-Sitosterol, Cholestan-3-one, Cholestanol and Stigmastanol, which appear with $\mathrm{MC} / \mathrm{PNEC}$ ratio ranging from 80-6849. In summer season only Stigmast-5-en-3-ol and Cholesterol are present, while in autumn no hormones (with the exception of Allopregnane used for medical treatment in dermatology) were detected in significant concentration levels. Hormones indicate human or animal fecal pollution, hence the presence of bacteria could also be expected in polluted water. Hexadecanoic acid and Pentadecaonic acid have been observed in all three seasons, but particularly in winter, with the $\mathrm{MC} / \mathrm{PNEC}$ ratio 4 times higher than in summer, and more than 80 times higher than in autumn. Caffeine (pharmaceutical, diuretic), as a good indicator for human refuse, is another compound detected with 
a significant ratio, but only in winter period, as is the pesticide Diazinon, with an MC/PNEC ratio of 730, due to its use as ear tags for cattle and as an insecticide. Pesticides and caffeine were not present in summer and autumn.

Contrary to the screening analysis, results obtained by target analysis show that during the autumn period PAHs were the most relevant compounds detected in wastewater and surface water in the Novi Sad area, while in summer mostly pesticides were indicated as the most relevant, which is expected due to high agricultural activity [23].

\section{Conclusions}

Conducted screening analyses resulted in the preliminary list of 300 compounds of concern in the Danube basin in Novi Sad area. Additional target analyses were focused on 69 compounds (WFD pollutants), of which 29 had values above LoD. All compounds were subjected to eco-toxicity analyses, which resulted in the derivation of PNEC values.

The combined results from screening and target analyses and eco-toxicity study were used for calculating prioritization ratio, and the list of the most relevant pollutants has been developed. The list contains 86 compounds detected within screening analyses and 27 compounds determined in target analyses, and it is the first list in the Balkan region, established by the approach adopted in the EU. The most hazardous group of compounds in Novi Sad are linear and branched alkanes, followed by hormones, pesticides, industrial chemicals, and PAHs.

Seasonal variation analysis confirmed that certain compounds occur independently in the season (e.g., hormones, alkanes), while other compounds such as pesticides (summer), and PAHs (autumn) are present only during particular seasons. The future research within seasonal variations will be focused on the impact of particular environmental factors (temperature, precipitation, etc.) on the pollutants' concentration levels and their PEC/PNEC ratio.

In compliance with WFD requirements, a prioritization approach should be applied every 4 years and, accordingly, monitoring programmes should be developed to include newly identified relevant pollutants.

\section{Acknowledgements}

This research was supported by the NATO Science for Peace Project EAP SFPP 984087, and partially supported by the Ministry of Education, Science, Research and Sport of the Slovak Republic within the Research and Development Operational Program for the project University Science Park of STU Bratislava, ITMS 26240220084, co-funded by the European Regional Development Fund; as well as project
Nos. III46009 and TR34014 funded by the Serbian Ministry of Education, Science and Technological Development.

\section{Conflict of Interest}

The authors declare no conflict of interest.

\section{References}

1. BABUT M., CORRINE B., MARC B., PATRICK F., JEANNE G., GENEVIEVE G. Developing environmental quality standards for various pesticides and priority pollutants for French freshwaters. Journal of Environmental Management. 69, 139, 2003.

2. VOJINOVIC MILORADOV M., MIHAJLOVIC I., VYVIURSKA O., CACHO F., RADONIC J., MILIC N., SPANIK I. Impact of wastewater discharges to Danube surface water pollution by emerging and priority pollutants in the vicinity of Novi Sad, Serbia. Fresenius Environmental Bulletin. 23, 2137, 2014.

3. MILIC N., SPANIK I., RADONIC J., TURK SEKULIC M., GRUJIC N., VYVIURSKA O., MILANOVIC M., SREMACKI M., VOJINOVIC MILORADOV M. Screening analyses of wastewater and Danube surface water in Novi Sad Locality, Serbia. Fresenius Environmental Bulletin. 23, 372, 2014.

4. CHAPMAN D., BRADLEY C., GETTEL G., GÁBOR HATVANI I., HEIN T., KOVÁCS J., LISKA I., OLIVER D., TANOS P., TRÁSY B., VÁRBÍRÓ G. Developments in water quality monitoring and management in large river catchments using the Danube River as an example. Environ Sci Policy. 64, 141, 2016.

5. LOOS R., TAVAZZI S., MARIANI G., SUURKUUSK G., PARACCHINI B., UMLAUF G. Analysis of emerging organic contaminants in water, fish and suspended particulate matter (SPM) in the Joint Danube Survey using solid-phase extraction followed by UHPLC-MS-MS and GC-MS analysis. Sci. Total Environ. 607-608, 1201, 2017.

6. HRUBIK J., GLISIC B., TUBIC A., IVANCEV-TUMBAS I., KOVACEVIC R., SAMARDZIJA D., ANDRIC N., KAISAREVIC S. Toxicological and chemical investigation of untreated municipal wastewater: Fraction- and speciesspecific toxicity. Ecotoxicol. Environ. Saf. 127, 153, 2016.

7. SREMACKI M., MILANOVIC M., MIHAJLOVIC I., SPANIK I., RADONIC J., TURK SEKULIC M., MILIC N., VOJINOVIC MILORADOV M. Adaptation of screening analysis method for key pollutants in wastewater of meat industry. Fresenius Environmental Bulletin. 25, 5008, 2016.

8. GRUJIC LETIC N., MILANOVIC M., MILIC N., VOJINOVIC MILORADOV M., RADONIC J., MIHAJLOVIC I., TURK SEKULIC M. Determination of Emerging Substances in the Danube and Potential Risk Evaluation. Clean (Weinh). 43, 731, 2015.

9. PETROVIC M., SKRBIC B., ZIVANCEV J., FERRANDOCLIMENT L., BARCELO D., Determination of 81 pharmaceutical drugs by high performance liquid chromatography coupled to mass spectrometry with hybrid triple quadrupole-linear ion trap in different types of water in Serbia. Sci. Total Environ. 468-469, 415, 2014. 
10. SKRBIC B., JI Y., DJURISIC-MLADENOVIC N., ZHAO $J$. Occurrence of the phthalate esters in soil and street dust samples from the Novi Sad city area, Serbia, and the influence on the children's and adults' exposure. J. Hazard. Mater. 312, 272, 2016.

11. SKRBIC B., MARINKOVIC V., ANTIC I., PETROVIC GEGIC A. Seasonal variation and health risk assessment of organochlorine compounds in urban soils of Novi Sad, Serbia. Chemosphere. 181, 101, 2017.

12. MIHAJLOVIC I., SABOLC P., SREMACKI M., BRBORIC M., BABUNSKI D., DJOGO M. Comparison of Spectrolyser Device Measurements with Standard Analysis of Wastewater Samples in Novi Sad, Serbia. Bull Environ Contam Toxicol. 93, 354, 2014.

13. KLEIN W., DENZER S., HERRCHEN M., LEPPER P., MÜLLER M., SEHRT R. Revised proposal for a list of priority substances in the context of the Water Framework Directive (COMMPS procedure), Schmallenberg, Germany: Frauenhofer-Institut, Umweltchemie und Ökotoxikologie. 29, 1999.

14. DAGINNUS K., GOTTARDO S., MOSTRAGSZLICHTYNG A., WILKINSON H., WHITEHOUSE P., PAYA-PÉREZ A. A modelling approach for the prioritization of chemicals under the water framework directive. JRC scientific and technical reports, Italy, Ispra: European Commission - Joint Research Centre. 48, 2010.

15. VON DER OHE P. C,. DULIO V., SLOBODNIK J., DE DECKERE E., KÜHNE R., EBERT R. U., GINEBREDA A., DE COOMAN W., SCHÜÜRMANN G., BRACK W. A new risk assessment approach for the prioritization of 500 classical and emerging organic microcontaminants as potential river basin specific pollutants under the European Water Framework Directive. Sci. Total Environ. 409, 2064, 2011.
16. MISZTAL A., KUCZERA M. An impact assessment of built up residential areas on selected water quality indexes. Pol. J. Environ. Stud. 17 (6), 985, 2008.

17. HAN J., CHEH J,. JIANG Z., CHEN L., JI. Volatile and semi-volatile organic compounds in the lower Yangtze river and surface waters of three Chinese provinces. Pol. J. Environ. Stud. 22 (3), 683, 2013.

18. DJOGO M., RADONIĆ J., MIHAJLOVIĆ I., OBROVSKI B., UBAVIN D., TURK SEKULIĆ M., VOJINOVIC MILORADOV M. Selection of optimal parameters for future research monitoring programmes on MSW landfill in Novi Sad, Serbia. Fresenius Environmental Bulletin. 26, 1329, 2017.

19. SLOBODNIK J., MRAFKOVA L., CARERE M., FERRARA F., PENNELLI B., SCHUURMANN G., VON DER OHE P. C. Identification of river basin specific pollutants and derivation of environmental quality standards: A case study in the Slovak Republic. Trends Analyt Chem. 41, 133, 2012.

20. CHAU H.T.C., KADOKAMI K., DUONG H.T., KONG L., NGUYEN T. T., NGUYEN T.Q., ITO Y. Occurrence of 1153 organic micropollutants in the aquatic environment of Vietnam. Environ. Sci. Pollut. Res. 25, 7147, 2018.

21. OUYANG Y., NKEDI-KIZZA P., WU Q., SHINDE D., HUANG C. Assessment of seasonal variations in surface water quality. Water Res. 40, 3800, 2006.

22. NET S., SEMPÉRÉ R., DELMONT A., PALUSELLI A., OUDDANE B. Occurrence, Fate, Behavior and Ecotoxicological State of Phthalates in Different Environmental Matrices. Environ. Sci. Technol. 49, 4019, 2015.

23. PEREIRA A.S., DAAM M.A., CEREJEIRA M.J. Evaluation of FOCUS surface water pesticide concentration predictions and risk assessment of field-measured pesticide mixtures - a crop-based approach under Mediterranean conditions. Environ. Sci. Pollut. Res. 24, 17394, 2017. 